\title{
The Underprepared College Student: How Non-Cognitive Factors Influence Academic Preparedness
}

\author{
Marni Finkelstein, Ph.D. \\ Department of Anthropology \\ John Jay College of Criminal Justice, United States \\ E-mail: mfinkelstein@jjay.cuny.edu \\ D. Moire Thom, Ed.D. \\ School of Advanced Studies, University of Phoenix \\ 3157 E. Elwood St., Phoenix, AZ 85034, United States
}

Tel: 1-505-927-7052Ｅ-mail: moiretomas@email.phoenix.edu

Received: Dec. 15, 2013 Accepted: December 27, 2013 Published: February 1, 2014

doi:10.5296/jse.v4i1.4764

URL: http://dx.doi.org/10.5296/jse.v4i1.4764

\begin{abstract}
The purpose of this exploratory phenomenological study was to explore the influence of non-cognitive factors on academic preparedness. Interviews were conducted with a sample of underprepared college students concerning several areas of non-cognitive factors: early educational factors; personal factors; affective factors; and, non-cognitive skill factors. The students' attitudes and experiences revealed several themes concerning the influence of non-cognitive factors and academic preparedness. Findings related to textual categories indicated personal factors such as the students' experiences of coming from a broken home and family strife, or personal issues such as alcohol abuse and bad decision-making skills were possible reasons for their negative educational experiences. Additionally, their narratives about their youth suggested a lack of parental involvement in their early educational experiences. Structural theme findings suggested the malleability of non-cognitive skill factors such as their creative and practical skills, as well as affective factors, were a positive influence on the students' motivation to continue their degree aspirations. Key findings included a creative
\end{abstract}




\section{Macrothink}

Journal of Studies in Education

ISSN 2162-6952 2014, Vol. 4, No. 1

synthesis using cognitive/non-cognitive distinctions that emerged from a deeper understanding discovered within textual categories and structural themes. This study has several implications, as well as recommendations for improving the academic preparedness of academically underprepared college students.

Keywords: Higher education, College students, Academic preparedness, Non-Cognitive assessments, Academic unpreparedness 


\section{Introduction}

The Higher Education Act (HEA) of 1965 reflected an American belief that everyone should have the opportunity to pursue a college education (Donniger, 2009). One outcome of this Act was the initiation of open-access policies that encouraged more students to attend college regardless of their academic preparedness by offering incentives of interest-free loans, part-time jobs, and need-based scholarships (Bankston, 2011; Mulvey, 2008; Salas, Portes, D'Amico, \& Rios-Aguilar, 2011). While open access policies were meant to increase accessibility to higher education, an unintended result has been a substantially higher increase in academically underprepared college students (Moss \& Yeaton, 2006).

There is a long-standing controversy in education about whether academic integrity and open-access policies can coexist (Donniger, 2009). Part of this controversy is based on colleges relying on only cognitive factors to assess both academically prepared and underprepared students, which may not be a reliable assessment of academic preparedness for all potential students (Moore, 2007; Schmitt Keeny, Oswald, Pleskac, Billington, Sinha, \& Zorzie, 2009; Sternberg, 2008). Most colleges in the United States do not consider non-cognitive factors, such as emotional stability, social skills, and persistence, when assessing students' academic preparedness (Boylan, 2009; Lindqvist \& Vestman, 2011). Furthermore, policy discussions in the U.S. often underrate the relevance of non-cognitive factors, despite the fact that some research has suggested that looking at non-cognitive factors alongside cognitive factors can increase the assessment accuracy of students' academic preparedness (Heckman, 2008; Schmitt et al., 2009; Sternberg, 2008). Without an accurate assessment of a college student's academic preparedness, it is impossible to design a targeted intervention that will help to address the academic needs of the underprepared (Boylan, 2009).

In order to investigate this issue further, this qualitative phenomenological study focused on the lived experiences of 16 academically underprepared students to explore the ways that non-cognitive factors influenced their academic preparedness. A better understanding of this influence may aid in developing better assessments of those students who are academically underprepared, and may help inform the development of targeted interventions for those students.

\section{Literature Review}

Many colleges provide higher education opportunities through open access to students who are underprepared for college-level courses (Moss \& Yeaton, 2006). However, simply providing opportunity may not be sufficient to deal with academically underprepared students, who may require further development and training to integrate them into higher education better (Boylan, 2008). In order to understand the needs of underprepared college students better, Bailey (2009) argued for a restructuring of assessments to include non-cognitive abilities to address academic preparedness.

Sternberg (2007) argued that intelligence should not only be measured by cognitive ability, but should also involve the ability to successfully adapt to non-cognitive environmental challenges. He used the theory of successful intelligence as a way to explain how students compensate for 
their weaknesses and adapt to their environmental challenges, and suggested that diverse gender and ethnic groups of individuals may have challenging cultural environments to overcome. As a result, they may develop practical and creative skills to survive their environment (Sternberg, 2010).

The shift in interest of research from a focus on cognitive measures to one of non-cognitive measures for student assessment is the result of a changing focus from selection and placement toward educational practice such as instruction and counseling (Gottfredson \& Saklofske, 2009). Boylan (2009) used non-cognitive affective factors to assess if students had determination, autonomy, and the willingness to seek help on assignments. He urged community colleges to use assessments that triangulate non-cognitive affective factors with cognitive and personal factors for targeted interventions to help academically underprepared college students.

There have been several recent studies that have been conducted to measure the role of non-cognitive factors in education. Schmitt, et al. (2009) conducted a study in which non-cognitive assessments were used to augment the Scholastic Achievement Test (SAT) assessment. Boylan (2009) incorporated non-cognitive (i.e., affective \& personal) factors with cognitive factors to develop targeted interventions for underprepared students. Sternberg (2008) focused on practical (i.e., implementing ideas) and creative skills (e.g., generating ideas) as non-cognitive factors necessary for life-skills. Griffin (2008) researched personal factors such as a missing, unemployed, or illiterate parent as risk factors for students dropping out of school. Boylan (2009) noted that personal factors such as childcare responsibilities and language barriers can influence homework study habits. Other researchers such as Fewell and Deutscher (2004) determined that early educational factors or maternal responsivity are influential non-cognitive factors which contribute to academic preparedness.

\subsection{Non-cognitive Assessments}

The SAT and the American College Testing (ACT) assessment are two standardized tests that have monopolized the college admissions process in the United States, and are used to assess analytical skills and memory (Sternberg, 2010; Burlison, Murphy, \& Dwyer, 2009). However, these cognitive skills make up only a few of the many skills that are necessary for college preparedness (Sternberg, 2010). Early educational researchers believed that a combination of narrow and broad cognitive abilities contributed to a general factor of intelligence ( $g$-factor) (Van Der Veer, 2007). However, more recent research has suggested that non-cognitive factors are equally as important to college students’ academic preparedness as cognitive skills. In studying the relationship between high IQ scores and non-cognitive skills, Borghans, Meijers, and Weel (2008) discovered that behaviors such as self-discipline and motivation are essential non-cognitive factors affecting cognitive test scores. Additionally, the non-cognitive factor of persistence suggested that an individuals' perseverance accounted for successful educational retention (Duckworth, Peterson, Matthews, \& Kelly, 2007).

Schmitt et al. (2009) demonstrated that non-cognitive measures incrementally increase the assessment accuracy of freshman students' academic preparedness during college admission when added to standard cognitive tests. Non-cognitive factors related to intrinsic motivation 
have a positive association with academic persistence (Kaufman \& Dodge, 2009). Other research has found that many learning issues were the result of a mismatch between the dominant culture (i.e., cultural norms within public education) and the children's natural abilities (i.e., language \& home cultural norms), leading to a disconnect between a student's natural non-cognitive talents and the public education system that values cognitive abilities (Vygotsky, 1978).

When academic advisors combine cognitive assessment data with non-cognitive information, the ability to focus educational interventions towards underprepared students increases (Boylan, 2009). Non-cognitive measures incrementally increase the assessment accuracy of freshman students' academic preparedness during college admission when added to standard cognitive tests (Schmitt, et al., 2009). Additionally, non-cognitive measures can increase the assessment accuracy of cognitive measures while increasing gender and ethnic diversity as well. One study of 222 students demonstrated that connectedness to teachers and importance of activities was positively related to intrinsic motivation. Further, those non-cognitive factors related to intrinsic motivation have a positive association with academic persistence (Kaufman \& Dodge, 2009).

Despite the wealth of research on non-cognitive factors and assessments, little research has been conducted from the perspective of college students themselves (Reid \& Moore, 2008). The gap in the literature is noticeable when combining different areas of non-cognitive factors to discover the ways that they each influence college students' academic preparedness. Prior research has looked at specific non-cognitive factors such as creative and practical skill factors relative to standardized testing (Sternberg, 2008), as well as affective factors and personal factors relative to cognitive assessments (Boylan, 2009). However, no research to date has combined many different areas of non-cognitive factors to discover the ways they influence academic preparedness.

\section{Methods}

In this study, qualitative phenomenological research methods were used to explore the ways that several non-cognitive factors have influenced college students' academic preparedness. By integrating aspects of interpretive phenomenological analysis structural themes, a modified combination of Giorgi’s (1985) and Moustakas's (1994) phenomenological methods were used to discover the essence of college students' academic experience.

\subsection{Participants}

The participants in this study consisted of 16 academically underprepared college students from a four-year college in the Southwest. The participants were from a variety of ethnic groups including Hispanic, White, Native American, and African American. Over half of the participant self-identified as Hispanic. All participants were enrolled in below college level courses at the college at the time of the study, and were over the age of 18.

\subsection{Data Collection}

The data in this study emerged from an analysis of in-depth, semi-structured interviews that were individually conducted with 16 underprepared college students. Interviews lasted between 30 minutes and an hour. The audio-recorded interviews were subsequently transcribed 
into verbatim digital text. Participants in the study received copies of the transcripts of their interviews to ensure that they were an accurate representation of their interviews, and the resulting textual categories. All participants were assigned pseudonyms to maintain confidentiality and anonymity.

Participants were asked about their lived experiences related to non-cognitive factors including personal factors (relationship to parents, parental unemployment, parental literacy); affective factors, (attitude towards learning, willingness to make an extra effort, willingness to seek help); non-cognitive skill factors (creativity and practical skills); and, early educational factors (educational experiences from pre-K through high school). The study aimed to answer the central research question: In what ways do non-cognitive factors as perceived and experienced by underprepared college students influence their academic preparedness? Five sub-questions helped to inform the answer to the central research question: (1) How do academically underprepared college students perceive their lived college experience? (2) What are the early educational experiences of academically underprepared college before and during K-12? (3) What are the experiences of academically underprepared students that may help or hinder their education? (4) What are the experiences of academically underprepared college students related to affective factors such as overcoming the challenges they face in obtaining a college degree? and, (5) What influences do creativity and practical skills have on academic preparedness?

Open-ended interview questions were developed from the main research questions with the purpose of understanding how the students' experiences with non-cognitive factors influenced their academic preparedness.

\subsection{Analysis}

Data analysis included integrating aspects of interpretive phenomenological analysis (IPA) such as commonalities, divergent perspective, and convergent perspective as explicated by Pringle, Drummond, McLafferty, and Hendry (2011), which included aspects of Moustakas's (1994) and Giorgi's (1985) phenomenological methods. In essence the analysis included: Acknowledging bias at appropriate moments; using NVivo 8 software to develop preconfigured categories; developing textual categories; developing structural themes with IPA aspects; and, synthesizing the relevant concepts.

Prior to analysis, a digital text of transcripts was inserted into the qualitative analysis software, and labeled with each participant's pseudonym. The software was essential for storage of similar participants' significant statements in manually created preconfigured categories, which aligned with the research sub-questions. Iterative readings of key phrases within every preconfigured category were followed by thoughtful reflection and using software queries to cluster similar significant statements.

Structural themes emerged through a similar inductive process of manually relating significant statements to the research questions in a discovery process. Additionally, aspects of IPA such as commonalities, divergent perspective, and convergent perspective were sought and found within significant statements to become themes as well. Through iterative readings of textual 
categories and structural themes, a creative synthesis adapted to the study was an attempt to make visible what was previously invisible.

\section{Results}

The initial interview transcriptions and resulting coding emanated from the research sub-questions and consisted of five preconfigured categories: college experiences; early educational factors; personal factors; affective factors; and, non-cognitive skill factors. Further streamlining and clustering significant statements resulted in four textual categories: lived experiences before K-12; lived experiences during K-12; lived experiences during college; and, non-cognitive factors. After further analysis, textual categories, structural themes, and integrated aspects of interpretive phenomenological analysis resulted in a creative synthesis of academic underpreparedness using four cognitive/non-cognitive distinctions of preparedness and underpreparedness. Structural themes are described within the discussion of each major category.

\subsection{Current College Experiences}

College experiences were positive for most participants. Using probing questions and imagination, participants' descriptions revealed an implicit structure of their college experience, such as being informed of available services and guidance for career planning.

While participants reported having good experiences during college, most learned about the availability of college support services through other students or instructors, rather than from the admissions counter. Serena noted, "I can be honest with you, most of the programs here, I have found out from other students." In addition, Delores reported, "I didn’t - don't remember ever getting anything from them.”

Students with learning disabilities reported obtaining information immediately during admissions. Phil said, "The first person I talked to was the lady of special needs. She was the one that set my courses. She's my advisor for now." However, after further probing, he explained that his mother was the one who found out about the services. In reference to the theme of guidance for career planning, John shared that he was motivated to plan for the future. He recalled, "We had little support groups within our own classes, and we thought what are you going to do? Where are you going from this? What do you want to do?" However, other students did not have this same experience. Tanya stated, "I don’t really recall anything right now... information access is definitely an issue on the campus."

\subsection{Experiences Related to Early Educational Factors Before and During K-12}

The exploration into this category suggested themes such as teacher involvement and parental involvement as the underlying structure. In reference to teacher involvement, Rachel reported, "Um, without their support and their understanding I probably would have never made it an effort to um, you know, there, to um, learn the way I did." Josephine recalled, "When I was in high school, I had a teacher - my English teacher, and she motivated me to write, write, and write.” However, these instances of teacher involvement were sporadic and most participants' experiences were negative concerning K-12. For instance, Delores explained, "K-12 you pretty 
much sat there, be quiet and it was almost like they were drilling something into you rather than letting you show the willingness of wanting to learn." Laura reported, "Junior High as it was as it was called back then was really hard because there was no one at school who really wanted to take the time to help me, and at home there was nobody."

However, while participants experienced some teacher involvement, most participants were not receiving much parental involvement at their home. As Rachel recalled, "I never had parents or adults to follow through on my education... that's where my failure started in my education." She also noted that, “...teachers had more of an impact on me... I grew up with my Mom who had a lot of medical and mental problems." James explained, "My father was an alcoholic, so he was never around... and my mom worked two jobs and she was a single parent with a mortgage and a car payment.”

\subsection{Personal Factors That May Help or Hinder Educational Experiences}

For this theme, participants were asked to describe a personal issue that either helped or hindered their ability to obtain a college degree. Jackie noted that her biggest issue toward obtaining a degree was “financial aid probably 'cause my mom doesn't work right now. She's on disability and stuff and my father, um, are currently unemployed." Also, some participants did not have a place to live. Laura explained, "I needed somewhere to live, and I was willing to live in the park, and come over here during the day, you know leave my dog outside parked, you know tied up so that I could go." Apollo reported, "I was like, homeless for, like, about a month. I had to stay in my girlfriend's car because I didn't have anywhere to stay; I had no money at the time." Although she was from a two-parent family, Jane reported family health issues in her home and as the oldest child she often cared for her mother. She said that she, "...had to play second mother because either my mom was sick or she was giving birth." She dropped out of school in the tenth grade because of family issues, which may have led to her academic underpreparedness.

Delores mentioned that her, "...high school years were not pleasant. I dropped out cause I was I was not happy and I wasn't learning anything in school cause I - I just hated getting up and going to school." Rachel reported "I wish they would have stressed to me more of the uh, taking it more of accountability and responsibility...it would have made it easier for me to stay in school. . . I never had parents or adults to follow through on my education."

Participants also reported that their own poor behaviors affected their academic preparedness. Serena reported a lack of guidance throughout her K-12 experience and eventually began drinking alcohol at age 13. Rachel added, "I regret the fact that I should have been in school rather than...falling through the cracks." Josephine noted, "What I love about my dad is, even though he drinks a lot, he’s always around...I was kind of like a trouble maker."

Conversely, some participants reported they had supportive families in which their parents controlled their education, or gave them incentives for good grades, and made them do chores around the home. For instance, Henry acknowledged, "My father control my education... he tells me like you going to take English... I say okay because anyway I have to go." 
John added, "We were always active at home and there were a lot of chores." These participants' lived experience were not the norm but do support the notion of an implicit complex structure that influences academic preparedness, as these participants reported only a few negative family issues.

\subsection{Affective Factors Used in Overcoming Educational Challenges}

Participants were asked to describe how they will overcome the challenges they face in obtaining a college degree. Based on the data, this issue suggested that structural themes such as confidence/self esteem; perseverance/determination, and self-regulation were influential toward academic preparedness.

Concerning perseverance/determination, Jane proclaimed, "I have set my mind to finish up what I started...I'm very determined... I'm up till all hours trying to study." Serena added that she, "...raised two children, lost one, and kept dusting myself and getting right back up... Sometimes I spend six, seven hours at the computer studying... I'm very determined to finish..."

Rachel noted, “I’ve had to learn through those struggles and be determined...I am determined to, to finish this education, even if it takes me longer than the 4 years. Tanya reported, "I'm very resilient and adapt well... perseverance is key."

Participants' perseverance/determination may have had some influence on their confidence/self esteem. Frank noted, “I'm more outgoing and outspoken and I have self confidence... without self confidence it will be hard to succeed in a college because you are on your own." Rachel acknowledged that, "...one of the things that I look on once I get my degree is my self esteem." When completed, James added, "I'll feel good about myself." David described his eventual degree completion as "a sense of personal fulfillment."

Participants overwhelmingly indicated that they had the perseverance and motivation to overcome their academic underpreparedness. For example, Jane proclaimed, "I have set my mind to finish up what I started...I'm up till all hours trying to study." Frank had a 5-year plan. He said, "My first step is obtaining my Associate's, which I will get within a year, and then I'll get my Bachelor's 2 years later and if everything goes great, I would like to go on for my Master's and get my CPA in Accounting. Josephine noted, "I will not let obstacles get to me, no matter what."

These affective factors of determination and perseverance converged with college support services in helping participants to overcome having little family emotional and financial support. Rachel noted that, “...if I wouldn’t have the ability of financial aid it would be rough." Delores, another participant with family issues, was adamant about her college support services. She said, “I’m getting tutoring for my algebra, and it's awesome.”

One participant provided evidence of having knowledge of their self-regulation abilities but referred to it as self control, and another participant referred to it as having control over his direction in life. For instance, David noted, “...there’s a certain, certain level of self-control, I guess, that I have over myself for, uh, pushing past the procrastination and getting that work 
done." John added, "I also was told I can change direction any time, which is true. By being told that, I was actually informed that they don't have a direction for you. You choose that." These statements may have significance because awareness of information about personal abilities such as choosing your own direction in life or knowledge of self-control may influence academic preparedness.

\subsection{The Influence of Creativity and Practical Skills on Academic Preparedness}

To explore this issue, participants were asked to describe educational experiences in which a teacher inspired them to think creatively or use practical skills. Finding suggest that participants coming into college may need to have an intrinsic reason to pursue the rigors of education, and the lack of creativity they felt in the classroom implies something important was missing in education. Delores noted, "I think being creative is very important. I think it helps the cognitive skills along, whereas if you just have the cognitive without the creation, then it doesn't come together." Apollo provided his insight on the issues when he said, "I can count the amount of people I see inspired by learning and developing their mental capacity and it would not be that much...education is not what it should be... I think that's where, um, uh, there's like a bridge - a broken bridge in a sense." Rachel revealed, "I think that it's important for teachers to inspire their students, to figure out a way for our students to stay in school.”

Participants also stressed that they become engaged more in academics through activities that maintain their interest. Lydia commented, "With my biology, even though it's difficult with lecture, or it's boring with the lecture, the lab is so much fun because it's hands on." She further mentioned that, "...my junior teacher, she like - she would give us an essay that we had to make up a story, so it made me think of my gosh, this is like so much fun, I wanna actually keep doing this because it's enjoyable." In another example Phil added, "The one class that does give me a way to express myself is my photography class...I have so many different ideas, like movies, music - everything in my mind."

Using a divergent perspective, it was found that most of the participants had a positive viewpoint of the importance of creative and practical skills, but at least one participant had a negative viewpoint. Frank noted, "I believe you need to be well rounded in order to survive in this kind of world we live in today." John added "Creative skills? Well, they help you and they're very important because they actually solve problems for you - your own creativity can solve a problem."

\subsection{Creative Synthesis of Academic Underpreparedness}

The creative synthesis of academic underpreparedness was developed by using cognitive and non-cognitive distinctions to reveal four types of academic preparedness and underpreparedness: Cognitively Prepared/Non-cognitively Prepared; Cognitively Prepared/Non-cognitively Underprepared; Cognitively Underprepared/Non-cognitively Prepared; and, Cognitively Underprepared/Non-cognitively Underprepared.

The term cognitively prepared was operationalized as participants' metacognitive ability to plan (e.g., home-schooling their children, planning a business, or planning entrance into a university). The term non-cognitively prepared was operationalized as participants' 
self-regulation ability to control their behavioral choices (i.e., control of thoughts, attention, and actions), which may result from family support. Self-regulation and metacognitive skills may provide a deeper understanding, which may help educational leadership understand how to address academic underpreparedness. This portion of the study accounted for the complexity between academic preparedness and underpreparedness.

\subsubsection{Cognitively Prepared/Non-cognitively Prepared}

The cognitively prepared/non-cognitively prepared distinction implied academic preparedness in both constructs. For example, the data results revealed that John had home-schooled his daughter and he was merely going to college and taking noncredit courses to give his daughter a sense of security while she was attending college. John noted, "I came with her because her not being ever in a classroom was a little scary for her, and I said, 'Don't worry, I'll go with you...' even though I've already got my diploma and stuff, but they didn't care so it was all right."

Innovations linking below college level courses and college level courses should address the presence of this type of student, not to separate the student, but to allow this student to work as a paid informal student mentor. As part of institutional practice, outreach activities may offer faculty training to understand the dynamics of different types of academic underpreparedness as well as provide stipends for students acting as informal mentors.

\subsubsection{Cognitively Prepared/Non-cognitively Underprepared}

In this distinction, cognitively prepared/non-cognitively underprepared respectively equated to meta-cognitive preparedness and underpreparedness in self-regulation skills. In one example, Tanya tested out of high school at the age of 16 and obtained an AA degree soon afterward. However, 14 years later she decided to return to college for a BA degree. She noted that, "...having to be divorced and trying to negotiate things with my youngest child is probably one of my biggest issues that's kept me from graduating." Her personal issue made her an at-risk student in college and qualified her as non-cognitively underprepared.

In addition, Frank was cognitively prepared because he entered a selective university directly after graduating from high school. However, his alcohol problem led to his dropping out of college. This suggests that he was an at-risk student and therefore non-cognitively underprepared. If Frank were to abstain from alcohol, he would have a greater chance of succeeding in college due to his strong family and school affiliations. Tanya and Frank were both cognitively prepared but non-cognitively underprepared, which may have lowered their ability to control their behavioral choices (i.e., control of thoughts, attention, and actions).

These cognitively prepared students also provided leadership skills at the college. John indicated that he was providing informal tutoring for other academically underprepared students. Frank indicated he was the president of a student organization at the college. Tanya mentioned that she belonged to an Honor Society at the college, and that she attended project planning meetings to help the community. These participants were cognitively prepared. 
Nonetheless, two participants were non-cognitively underprepared to self-regulate. Frank had to stay away from drinking alcohol and Tanya had a troublesome alcoholic ex-spouse and children, which presented scheduling issues. While they may become good basic skill mentors, they may need additional training with self-regulation to assist them with becoming non-cognitively prepared. This finding was consistent with Vukman and Licardo (2010), who advocated using self-regulation to find alternatives when encountering obstacles to one's goals. Berger (2011) implied that interventions focused on self-regulation such as setting goals, monitoring self-progress, and note taking were a form of self-regulated learning in which learners become aware of their limitations and strengths and become proactive in their learning. Innovative institutional outreach may provide these students with an improved ability to make behavioral choices, set goals, and monitor self-progress.

\subsubsection{Cognitively Underprepared/Non-cognitively Prepared}

The cognitively underprepared/non-cognitively prepared distinction was defined as metacognitively underprepared with self-regulation preparedness. However, while assessing participants for this distinction, it was discovered that some participants who may have been non-cognitively underprepared during K-12 were non-cognitively prepared during their entry into college due to increased family support.

In Jane's circumstance, the family health issues that held her back during her K-12 experience were absent during college, therefore, her family supported her college aspirations. Henry had strong family support from the beginning, and he was only cognitively underprepared because of his not being fluent in English. He noted, "...like math, physics and chemistry, I'm really good at that, but the good thing here is like they prepare you for talking." Because of his strong family support, Henry met the criteria of non-cognitively prepared to overcome his cognitive language difficulties.

Lydia was cognitively underprepared because of her not receiving the extra support needed for her learning disability during most of her early educational experiences, but that changed during high school. Although she was from a broken home during K-12, she presently has strong family support from her mother, aunt, and uncle, which makes her non-cognitively prepared to overcome her learning disability challenges.

These participants were potentially meta-cognitively underprepared but non-cognitively prepared to self regulate their behavioral choice processes. Interestingly, of the four participants in this distinction, three participants were from stable two-parent families with reported family issues in one family. However, these issues were health issues not family strife. One possible common reason for these four participants' academic underpreparedness may be a subpar K-12 educational system. However, this reason has not been validated.

The students in this category may need cognitive improvement. However, the literature suggests that focusing merely on cognitive improvement may be ineffective. Heckman (2008) revealed cognitive improvement alone was largely ineffective for adults because of low cognitive brain malleability during late adolescence and adulthood, which may indicate a need for outreach training in metacognitive skills. Metacognitive skills are a way for students with 
low cognitive intelligence quotient (IQ) to compensate and become academically prepared (Dunlosky \& Metcalfe, 2009). Innovative institutional outreach may provide these students with stipends as an informal non-cognitive skills mentor.

\subsubsection{Cognitively Underprepared/Non-cognitively Underprepared}

This distinction was defined as academically underprepared in both metacognitive and self-regulation skills. The only discernible difference between this group of participants and the other groups was that $78 \%$ of participants in this distinction were from broken families. Although a two-parent family does not guarantee the cognitive or non-cognitive preparedness of the participant, it does suggest an improved chance that participants may have preparedness in one of these two cognitive/non-cognitive distinctions.

Most participants were underprepared in both cognitive and non-cognitive distinctions, which may suggest a lack of self-regulation and meta-cognitive skills. For example, Serena was a high school dropout from a broken home but returned to obtain a college degree within seven years of dropping out. She was cognitively underprepared because of this long absence from school. She noted, "I got straight into algebra and I hadn't taken a math class in quite some time so, it was a little difficult." She was non-cognitively underprepared because of a personal issue (i.e., drinking alcohol from the age of 13 years) and she admitted, “...to creating my own obstacles for many years." While Serena may have stopped drinking alcohol during college, she also has very little family support, which potentially qualifies her as an at-risk student and non-cognitively underprepared.

Josephine was from a broken home and the father of her daughter was alcoholic. Because of a lack of family support, she was seen as an at-risk student and non-cognitively underprepared for college. Rachel was a high school dropout during the $10^{\text {th }}$ grade but returned to school 20 years later. She was cognitively underprepared because of the long period away from school. She also lacked self-esteem. She noted, "One of the things that I look on once I get my degree is my self esteem." As a student with a learning disability and from a broken family, Rachel was seen as an at-risk student and therefore non-cognitively underprepared for college.

Delores was categorized as cognitively underprepared because she was a high school dropout who returned after 19 years from school. She noted, "It's - um, I'm learning a lot more, I mean, whereas before I didn't have - I didn't feel there was a reason for - for what we were doing." She was non-cognitively underprepared because she has no family support and she has a tendency to make bad decisions. She mentioned that, she, "...dropped out cause I was - I was not happy and I wasn't learning anything in school cause I - I just hated getting up and going to school.”

Jackie was from a broken family with at least one abusive parent, but managed to graduate from high school and go directly to college. In addition, she used many tutoring services, which was the reason for her classification as cognitively underprepared for college level coursework.

Apollo graduated from high school and went directly into college. However, he is not fluent in English, which resulted in his being cognitively underprepared. He was also from a broken family, and was living out of his girlfriend's car at the beginning of college. Apollo noted "I 
had to stay in my girlfriend's car because I didn’t have anywhere to stay; I had no money at the time." He was non-cognitively underprepared because of this reason.

\section{Discussion}

\subsection{Structural Themes}

Giorgi (1985) described structural themes as building the structure of participants' experiences within the phenomenon. In this study, the structure of the phenomenon was built by using the research sub-questions as a guide and iterative readings of every invariant constitute within textual categories. The structural themes uncovered in this study revealed several important issues concerning the influence of non-cognitive factors on academic preparedness.

The students' early experiences during grades K-12 were suggestive of mainly negative influence on college students' academic preparedness. Providing internships for K-12 students and invitations to parents of K-12 students to attend program events would help develop linkages and relationships with external parties for improving students' academic preparedness. Despite their negative early academic experiences, participants indicated mainly positive experiences while attending college. However, they were not informed of available services or guidance for career planning at the admissions counter. Levin, Cox, Cerven, and Haberler (2010) recommended that colleges connect every curriculum offered to students with student support services.

The findings of this study also suggest that personal factors may hinder academic preparedness. By including personal factors with cognitive factors during the academic assessment of new students, academic advisors can appropriately target student interventions. As suggested by Griffin (2008), underprepared students may need an encouraging academic environment to prepare them academically and to promote their self worth. As the findings of this study suggest, self-worth, self-confidence, and determination are important affective factors for students to utilize in overcoming challenges in obtaining their degrees. Bailey (2009) found that using only cognitive training within developmental education may account for only minimal degree attainment. Using an instructional specialist with a committee of students as constituents may help with this issue.

Creativity and practical skills were suggestive of ways non-cognitive skill factors have a positive influence on the academic preparedness of underprepared college students. Participants may need to learn to integrate creative skills and practical skills with cognitive skills to accomplish successfully accomplish their academic goals, and develop self-control. This finding is consistent with Sternberg's (2008) contention that a set of integrated skills is necessary for individuals to become successful in obtaining their goals. Thematic findings suggested a disconnection between cognitive skills and non-cognitive skills, leading to a need for public educational leadership to acknowledge the equal importance of non-cognitive skills.

\subsection{Creative Synthesis Discussion}

Most of the participants in the study were in the cognitively underprepared/non-cognitively underprepared category. The participants' statements and the literature review suggest that 
personal issues contribute to inconsistent actions and lack of goal setting during the K-12 experience. Morisano and Shore (2010) implied self-regulation may provide the basis for persistent action and further implicated personal goal setting as a direct engagement to address academic underpreparedness. Outreach programs may need to focus on students' self-regulation skills, meta-cognitive skills, and cognitive skills, as these skills provide a foundation for academic preparedness.

Since this category represents students who experience both cognitive and non-cognitive underpreparedness, it may represent a more challenging level of academic underpreparedness. Those who are classified within this category may require alternative perspectives, where self-regulation becomes a balance between cognitive control and emotional arousal. Students' awareness of an optimal balance may improve their academic preparedness. Vukman and Licardo (2010), argued that self-regulation of meta-cognitive skills was an important indicator of academic preparedness. They suggest that outreach programs to students should include the self-regulated learning strategies of planning, monitoring, regulation, and, reflection, and linking them to academic achievement outcomes. The formation of these non-cognitive auxiliary skills may become a viable solution for improving academic preparedness.

\section{Research Limitations}

The research findings were only generalizable to colleges that have similar diverse ethnic populations of academically underprepared college students. In addition, the small sample size of 16 underprepared college participants was a limitation. Although the current study may not be fully generalizable to the larger population, it was an important step toward establishing ways that non-cognitive factors may influence students' under-regulated emotional system, thereby influencing their academic preparedness.

\section{Recommendations}

Based on textual categories, structural themes, and creative synthesis, the first recommendation is to make learning enjoyable with less focus on lecturing while demonstrating practical, creative, and cognitive skills to develop life skills. Mathews (2010) reported students exhibited apathetic behaviors when a lack of hands-on activities and a lack of personal support were evident in the classroom. The current exploratory study revealed that these non-cognitive factors may have an integral and implicit complex structure of influence on academic preparedness.

The second recommendation entails providing self-regulation knowledge support for every student. This may improve students' metacognitive planning skills, which may enhance their academic preparedness. According to Vukman and Licardo (2009), self-regulation of metacognitive skills is an important indicator of academic preparedness. Dunlosky and Metcalfe (2009) suggested students with a low IQ may compensate and become academically prepared through their non-cognitive skills. Leadership in education may increase retention rates as well as improve the learning potentials of all students by making them aware of their self-regulation and meta-cognitive abilities, and training them to improve these abilities. 
The third recommendation entails providing college support services for every student, whether they seem to need it or not as a way to greet every student with a supportive and cohesive education atmosphere. While colleges offer many important support services, not all students become aware of these services during their enrollment period. Bailey (2009) noted both academically prepared and academically unprepared students have difficulty with their classes and recommended providing information about assistance for every student.

\section{Conclusion}

This exploratory study focused on the influences of non-cognitive factors on college students' academic preparedness from the academically underprepared college student's perspective. The results of this study indicate how non-cognitive factors influence college students' academic preparedness in a variety of complex ways.

Just as the Binet questionnaire became the foundation for IQ testing, non-cognitive questionnaires could become the foundation for new cognitive/non-cognitive life skills tests that would consider both non-cognitive and cognitive factors. The possibility of using non-cognitive factors combined with cognitive factors as the foundation for U.S. public education policy may require future research to deal with the ever-growing population of underprepared adolescents and adults entering college. Research into how non-cognitive factors affect self-regulation and meta-cognitive skills among the developmental periods of late adolescence and adults could benefit from future research, as self-regulation and metacognition may help academic underprepared college students compensate for low IQ.

\section{References}

Bailey, T. (2009). Challenge and opportunity: Rethinking the role and function of developmental education in community college. New Directions for Community Colleges, 2009 (145), 11-31. http://dx.doi.org/10.1002/cc.352

Bankston, C. L. (2011). The mass production of credentials: Subsidies and the rise of the higher education industry. The Independent Review, 15(3), 325-349.

Berger, A. (2011). Self-regulation: brain, cognition, and development. Washington, DC: American Psychological Association.

Borghans, L., Meijers, H., \& Weel, B. (2008). The role of non-cognitive skills in explaining cognitive test scores. Economic Inquiry, 46(1), 2-12. http://dx.doi.org/10.1111/j.1465-7295-2007.00073.x

Boylan, H. (2008). How research contributes to access and opportunity around the world. Journal of Developmental Education, 32(1), 2-3.

Boylan, H. (2009). Targeted intervention for developmental education students (T.I.D.E.S.). Journal of Developmental Education, 32(3),14-23.

Burlison, J., Murphy, C., \& Dwyer, W. (2009). Evaluation of the motivated strategies for learning questionnaire for predicting academic performance in college students of varying scholastic aptitude. College Student Journal 43(4), 1313-1323. 
Cunha, F., \& Heckman, J. J. (2008). Formulating, identifying and estimating the technology of cognitive and noncognitive skill formation. Journal of Human Resources, 43(4), 738-782.

Cunha, F., \& Heckman, J. J. (2009). The economics and psychology of inequality and human development. Journal of the European Economic Association, 20(2), 235-253.

Doninger, L. (2009). Remedial reading and college courses: Learning to read or reading to learn? A study of practices in a community college in New England (Doctoral dissertation, Johnson \& Wales University). Available from ProQuest Dissertations \& Theses. (UMI No. 3350023)

Duckworth, A., Peterson, C., Matthews, M., \& Kelly, D. (2007). Grit: Perseverance and passion for long-term goals. Journal of Personality and Social Psychology, 92(6), 1087-1101. http://dx.doi.org/10.1037/0022-3514.92.6.1087

Dunlosky, J., \& Metcalfe, J. (2009). Metacognition. Thousand Oaks, CA: Sage Publications.

Fewell, R. R., \& Deutscher, B. (2004). Contributions of early language and maternal facilitation variables to later language and reading abilities. Journal of Early Intervention, 26(2), 132-145

Giorgi, A. (1985). Sketch of a psychological phenomenological method. In C. Aanstoos, W. F. Fischer, A. Giorgi, \& F. J. Wertz, (Eds.), Phenomenology and psychological research. Pittsburgh, PA: Duquesne University Press.

Gottfredson, L., \& Saklofske, D. (2009). Intelligence: Foundations and issues in assessment. Canadian Psychology, 50(3), 183-195. http://dx.doi.org/10.1037/a0016641

Griffin, J. G. (2008). A case study: The preparedness of adult education students for college-level education (Doctoral dissertation, Liberty University). Available from ProQuest Dissertations \& Theses. (UMI No. 3330976)

Heckman, J. J. (2008). Schools, skills, and synapses. Economic Inquiry, 46(3), 289-324. http://dx.doi.org/10.1111/j.1465-7295.2008.00163.x

Kaufman, A., \& Dodge, T. (2009). Student perceptions and motivation in the classroom: exploring relatedness and value. Social Psychology of Education: An International Journal, 12, 101-112. http://dx.doi.org/10.1007/s11218-008-9070-2

Levin, J., Cox, E., Cerven, C., \& Haberler, Z. (2010). The recipe for promising practices in community colleges. Community College Review 38(1), 31-58. http://dx.doi.org/10.1177/0091552110374505

Lindqvist, E., \& Vestman, R. (2011). The labor market returns to cognitive and non-cognitive ability: Evidence from the Swedish enlistment. American Economic Journal, 3(1), 101-128. http://dx.doi.org/10.1257/app.3.1.101

Mathews, C. (2010). A phenomenological case study: Motivating apathetic students to complete their class assignments (Doctoral dissertation, University of Phoenix). Available from ProQuest Dissertations and Theses. (UMI No. 3425725) 
Moore, R. (2007). Course performance, locus of control, and academic motivation among developmental education students. Research \& Teaching in Developmental Education, 24(1), 46-63.

Morisano, D., \& Shore, B. M. (2010). Can personal goal setting tap the potential of the gifted underachiever? Roeper Review, 249-258. http://dx.doi.org/10.1080/02783193.2010.508156

Moss, B. G., \& Yeaton, W. H. (2006). Shaping policies related to developmental education: An evaluation using the regression-discontinuity design. Educational Evaluation and Policy Analysis, 28(3), 215-229.

Moustakas, C. (1994). Phenomenological research methods. Thousand Oaks, CA: Sage Publications, Inc.

Mulvey, M. E. (2008). Under-prepared students: A continuing challenge for higher education. Research \& Teaching in Developmental Education, 24(2), 77-87.

Pringle, J., Drummond J., McLafferty, E., \& Hendry, C. (2011). Interpretative phenomenological analysis: A discussion and critique. Nurse Researcher, 18(3), 20-24.

Reid, M. J., \& Moore, J. L. (2008). College readiness and academic preparation for postsecondary education: Oral histories of first-generation urban college students. Urban Education, 43(2), 240-261. http://dx.doi.org/10.1177/0042085907312346

Salas, S., Portes, P. R., D'Amico, M. M., \& Rios-Aguilar, C. (2011). Generacion 1.5: A cultural historical agenda for research at the 2-year college. Community College Review 39(2). 121-135. http://dx.doi.org/10.1177/0091552111405037

Schmitt, N., Keeney, J., Oswald, F., Pleskac, T., Billington, A., Sinha, R., \& Zorzie, M. (2009). Prediction of 4-year college student performance using cognitive and non-cognitive predictors and the impact on demographic status of admitted students. Journal of Applied Psychology 94(6), 1479-1497. http://dx.doi.org/10.1037/a0016810

Sternberg, R. J. (2007). Right answer to the wrong question: A reply to Jung and Haier. Behavioral and Brain Sciences, 30(2), 170-171. http://dx.doi.org/10.1017/S01405 25X0700 1306

Sternberg, R. J. (2008). Applying psychological theories to educational practice. American Educational Research Journal, 45(1), 150-165. http://dx.doi.org/10.3102/0002831207312910

Sternberg, R. J. (2010). College admission for the $21^{\text {st }}$ century. Cambridge, MA: Harvard University Press.

Van Der Veer, R. (2007). Lev Vygotsky. Norfolk, UK: Biddles.

Vukman, K., \& Licardo, M. (2010). How cognitive, metacognitive, motivational and emotional self-regulation influence school performance in adolescence and early adulthood. Educational Studies, 36(3), 259-268. http://dx.doi.org/10.1080/03055690903180376

Vygotsky, L. (1978). Mind in society: The development of higher psychological processes. Cambridge, MA: Harvard University Press. 